\title{
BMJ Open Micro-phenomenological approach to explore the patient experience during an initial spirometry examination to diagnose COPD in general practice in France
}

\author{
Matthieu Bremond, ${ }^{1,2}$ Anthony Berthelot, ${ }^{3}$ Laurent Plantier, ${ }^{2,4,5}$ Hervé Breton, ${ }^{1,2}$ \\ Maxime Pautrat (iD) 2,3
}

To cite: Bremond $\mathrm{M}$, Berthelot A, Plantier L, et al. Micro-phenomenological approach to explore the patient experience during an initial spirometry examination to diagnose COPD in general practice in France. BMJ Open 2021;11:e049121. doi:10.1136/ bmjopen-2021-049121

- Prepublication history for this paper is available online. To view these files, please visit the journal online (http://dx.doi. org/10.1136/bmjopen-2021049121).

Received 19 January 2021 Accepted 11 June 2021

\section{Check for updates}

(C) Author(s) (or their employer(s)) 2021. Re-use permitted under CC BY-NC. No commercial re-use. See rights and permissions. Published by BMJ.

${ }^{1}$ Department of Education and Training Sciences, University of Tours, Tours, France ${ }^{2}$ EA7505 EES, University of Tours, Tours, France

${ }^{3}$ Faculty of Medicine, University of Tours, Tours, France

${ }^{4}$ Department of Pulmonology and Functional Respiratory Exploration, CHRU Tours, Tours, France

${ }^{5}$ INSERM UMR 1100, University of Tours, Tours, France

Correspondence to Dr Maxime Pautrat; maxime.pautrat@univ-tours.fr

\section{ABSTRACT}

Objectives To explore the patient experience of a spirometry test used to confirm chronic obstructive pulmonary disease (COPD) diagnosis in patients with suspected smoking-related COPD.

Design This is a qualitative study, performed with open interviews in adults following a routine spirometry test to confirm COPD diagnosis. Data were analysed with a phenomenological-inspired micro-phenomenology approach. Participants Eligible patients were recruited through their general practitioner, 10 were interviewed.

Setting Primary care in Centre-Val-De-Loire area, France, in 2018.

Results Participants reported the spirometry test experience as being unfamiliar but gave meaning to the symptoms they experience. Participants expressed a desire to perform the test well and a willingness to confront their state of health. After the spirometry had been completed and the results announced, participants moved through stages of grief from their pre-spirometry self and symptom perception to a state of acceptance. Overall, participants expressed a narrative of an evolving cognitive and corporeal awareness during this spirometry experience. The verbatim quotes describe a cognitive rupture with their chronic illness usually considered as a 'way of life'.

Conclusions A spirometry test goes beyond a diagnostic value, providing patients with an opportunity to gain awareness of their own state of health, reframe their breathlessness-related limitations and thus begin to accept the disease. These awareness gains may be considered as small steps towards health behavioural change. Spirometry may have educative potential and support lifestyle changes.

\section{INTRODUCTION}

Chronic obstructive pulmonary disease (COPD) is currently the third leading cause of death in the world, and in France, an estimated 3.5 million people are affected. The annual social cost is € $€ .5$ billion and mortality is 16000 patients per year. ${ }^{12}$ This burden made COPD a public health priority topic in $2018 .^{3}$
Strengths and limitations of this study

- To avoid subjective bias, the researchers coded the verbatim quotes separately and then cross-checked their findings.

- This interview method allows participants to express themselves freely about their real-life experience; thus, it decreases the risk of sociability bias and increases the internal consistency.

- The use of spirometry is not widespread in primary care in France, which may account for the small number of participants.

- The elicitation interview method may have been limited in this specific population due to participant low level of insight into the procedure. This may account for the unusually short interview length compared with the descriptive phenomenological approach.

COPD is a complex, systemic disease that progresses slowly and insidiously, gradually reducing physical activity levels. Phenomenological studies suggest that COPD involves physical, social, psychological and emotional components, meaning patients adapt their lifestyle to their respiratory status over time. ${ }^{4-6}$ This adaptive strategy draws people living with COPD into a downward spiral of physical and psychosocial deconditioning that greatly impacts their quality of life. ${ }^{7}$ Also, the slow disease progression enables many patients to avoid accepting their declining health and eventual mortality. ${ }^{8}$ Although some people with COPD engage coping strategies, many do not and instead, become psychologically and emotionally distressed, continuing to deny their ill health. ${ }^{9}$ Most patients express 'accepting' COPD as a 'way of life'. ${ }^{10}$ Using this acceptance strategy means that people adapt their daily living activities to their reducing breathing capacities. However, 
this strategy reinforces the denial coping mechanism, preventing patients from becoming aware of their disease and identifying opportunities ${ }^{411-13}$ which may slow down further deterioration of their condition. For an individual to become aware that their feeling of being ill is a disease, they require a clear diagnosis. Understanding the diagnosis allows individuals to accept the symptoms and act to slow the progression associated with COPD. ${ }^{14}{ }^{15}$ Breaking with denial and recognising personal limitations related to their symptoms forces patients to deal with the illness. ${ }^{6} 16$

Disease acceptance is the first step towards engaging patients to manage their breathlessness. ${ }^{17}$ When patients are empowered to manage their health, they experience less exacerbation, adhere better to medication and have better quality of life. ${ }^{17-19}$ Some health behavioural change models examine patient experience as part of the decision-making process with an identified tipping point of opportunity for change. ${ }^{20}$ One tipping point for patients with a chronic condition is the minimum belief needed in order to make changes that improve their quality of life. For example, the importance of the problem in the patient's life, the level of opportunity in their lifetime to take action and self-confidence in their ability to achieve this change.

Spirometry is required to diagnosis COPD. When COPD is diagnosed early, patients report less exacerbation compared with undiagnosed patients. ${ }^{21} 22$ Thus, using spirometry for early COPD diagnosis is justified in primary care. ${ }^{23-25}$ Although the validity and feasibility of spirometry for COPD diagnosis have been shown in primary care ${ }^{2627}$ its use is suboptimal in France, requiring a motivated clinician ${ }^{28-30}$ and patient collaboration to correctly perform the forced exhalation manoeuvre.

Little is known about the effect the first spirometry test has on raising patient awareness about their symptoms in primary care. Although concepts such as 'Lung Age' have been used to foster smoking cessation, ${ }^{31}$ spirometry has yet to be shown to motivate patients to change their behaviour and accept their diagnosis. These techniques may be useful for a stepwise improvement in the delivery of care to patients with chronic respiratory conditions.

The aim of this study was to explore the patient experience following a spirometry test in primary care to determine if this experience could meet criteria for health behavioural change.

\section{METHODS}

\section{Study design}

\section{The phenomenological interview}

Micro-phenomenology is a novel analytical technique to measure the introspective, personal view of an experience by exploring visual, emotional and auditive experiences around the reference event. ${ }^{32-34}$ This approach was inspired by the more complex phenomenological approach, which challenges the concept of disease, whereby signs and symptoms are mediated by cultural ideas of illness. ${ }^{35}$ The interview technique was inspired by an explanatory interview developed by the French psychologist Pierre Vermersch. Using this technique to elicit the patient experience, the interviewer evokes a past experience within the interviewee, who in turn re-enacts the experience during an open interview. This technique allows researchers to explore the reference event from the pre-reflected consciousness (implicit) to the thoughtful consciousness (explicit). ${ }^{36}$ This micro-phenomenology technique has previously been shown to evoke experiences commonly encountered in primary care, such as acute onset of pain in chronic pain diseases. ${ }^{37}$

\section{Participants}

Ten adults who had spirometry-confirmed, smokingrelated COPD participated in this study of which, six were men and four were women, aged between 40 and 76 years (mean 59). The mean age was 59 years (range: 40-76 years) and lung function (mean forced expiratory volume in one second) was $62 \%$ (range: $35 \%-85 \%$ ). Seven were active smokers and three were ex-smokers and a smoking history that ranged from 10 to 40 pack-years (mean 26). Participants were excluded if they had a history of asthma, advanced heart failure, pre-existing COPD diagnosis, did not speak French or had dementia. The snowball sampling method was used to ensure a diverse selection of patient characteristics was obtained: age, gender, socioeconomic status. Six participants lived in a rural environment, four had retired, five were in current employment and one was unemployed. Among those with current or previous employment, six were manual workers, three were office-based workers and one was a health professional. All but three participants were being treated with inhaled therapy for their respiratory symptoms.

\section{Patient recruitment}

Patients with suspected COPD were recruited by general practitioners (GPs) in two rural and one urban general practice in the Centre-Val-de-Loire region of France. All GPs were experienced with spirometry and were practising in multidisciplinary care centres. Once a GP had informed an eligible participant about the study, the researcher $(\mathrm{AB})$ approached them by telephone. All interested participants took part in the interviews.

\section{Study procedure and data collection}

The research team (MB, $\mathrm{AB}$ and $\mathrm{MP}$ ) developed an open interview guide with phenomenological prompts and probes focused on the spirometry test experience. A pilot test was unnecessary for an open interview. Patients were not asked to explain or make sense of the reference event. Speech authenticity was respected, and follow-up prompts were intended only to encourage participants to recount their personal experience. Data saturation was not required for this micro-phenomenological approach as the objective was to identify and understand shared features in this lived experience. Thus, a sample size of 10 patients was considered sufficient to elicit common structures. 
The interviews were conducted up to 3 months after the spirometry test was performed and took place in the patient's usual primary care setting. The investigator (AB) introduced himself as a medical student specialised in general practice. He had no previous connection with the participants. After providing their consent to participate in the study, participants were asked to describe their thoughts at three specific time points: before spirometry, at the time of spirometry and at the announcement of results. The interviews were performed once and recorded with a mobile phone, the verbatim quotes transcribed, anonymised and labelled. Additional field notes were made during the interviews and included in the analysis. The participants were given the opportunity to stop at any time and were informed that their responses and personal information would remain anonymous. No time limit was expected for the interview apart from the defined time points. The interview was structured according to Vermersch. ${ }^{36}$

\section{Reliability criteria}

The investigator $\mathrm{AB}$ was trained in microphenomenological technique and all researchers involved in data collection and analysis had previous experience in conducting qualitative research studies.

To avoid subjective influence, investigators remained impartial, laying aside theoretical knowledge, a priori and the expected answers. Analysts remained impartial and willing to be surprised by the results.

\section{Data analysis}

The analysis was performed in accordance with the process described by Valenzuela-Moguillansky et al. ${ }^{38}$ The coding framework consisted of six steps as outlined in table 1. Before data analysis, investigator triangulation was performed to obtain a comprehensive picture. The results a priori were elucidated from four investigators: two GPs, one physiotherapist and one narrative medicine specialist. The investigators used an iterative process and were careful to allow the themes to emerge from the data. After consensual discussion among investigators, these data were converged and grouped into three categories, according to the description criteria for experience in the phenomenological approach (cognitive, perception and feeling). ${ }^{39}$ These three categories provide a conceptual framework in which patients make health behavioural changes.

\section{Patient and public involvement}

Patients and/or the public were not involved in the design, or conduct, or reporting, or dissemination plans of this research.

\section{RESULTS}

Ten people agreed to participate and were interviewed. The interviews were carried out between 26 July 2017 and 18 March 2018 with a mean duration of 27.15 min (range: 20-37 min). The transcripts were numbered EX-EY and the emergent categories are presented here in chronological order before, during and after the spirometry text experience. To illustrate the context for the reported experiences, the emergent categories derived from the data are presented chronologically: before, during and after spirometry, in the present tense, including only meaningful words.

\section{Before spirometry}

Before their first spirometry, the participants described feeling as if they were getting involved in a mysterious experiment. Although willing, they felt apprehensive about discovering the reason for their ill health. "There's a moment you have to...dot the i's and cross the t's, see what happens, so here we go...let's go" (E1). Discovering the device was a new, unusual experience for these patients: "I was not used to doing this ... these tests ..." (E3), “...because I did not know that stuff” (E8). For some, having confidence in their doctor made the feeling of uncertainty for the future diagnosis more bearable. “... after all, we never know what is in store for us, ... so we look everywhere but ... it's my doctor, I'm confident ..." (E7). Patients also reported feeling apprehensive about

Table 1 The six steps of coding framework

\begin{tabular}{ll}
\hline Steps & Objectives \\
\hline Step 1: listen, read and reread the interview & $\begin{array}{l}\text { Data immersion and entry into the participant's world } \\
\text { (comprehensive approach) }\end{array}$ \\
Step 2: initial annotations & $\begin{array}{l}\text { Produce a set of comprehensive and detailed notes and } \\
\text { comments on the data considering the semantic content of the } \\
\text { speech as well as the language used by the participant }\end{array}$ \\
Step 3: develop emerging themes & $\begin{array}{l}\text { Produce themes reflecting both the participant's discourse and } \\
\text { the analyst's active interpretation process }\end{array}$ \\
Step 4: identify links between emerging themes & $\begin{array}{l}\text { Produce a structure capable of reflecting the most interesting } \\
\text { and important aspects of the participant's story by grouping and } \\
\text { linking the themes produced in the previous step }\end{array}$ \\
$\begin{array}{l}\text { Step 5 and 6: move on to the next case and search for links } \\
\text { between the interviews }\end{array}$ & $\begin{array}{l}\text { Apply steps 1-4 on a new interview then search for links between } \\
\text { the different interviews selected for analysis }\end{array}$
\end{tabular}


breathing into the device. "Then suddenly I was told: 'Ok, we will have you blow in the machine"”(E1). "In fact, it's super scary! I say to myself I hope it's okay ... I'm not going to be too sick ..." (E9). "We know but we do not want to know; we have strong doubts" (E1). Patients also experienced somatic symptoms of stress before breathing into the device. "I'm starting to stress" (E10), "my heart is beating at 150" (E1). "I had the feeling my whole body was tense" (E1). "Few sweats and knots in the stomach" (E9). "My stomach is tying itself in knots and I say to myself, 'this is happening ... well, what are we going to find?" (E10). Patients also expressed feeling stressed about the expected outcome of the examination. "We know, but we don't want to know; we have strong doubts" (E1). "I tell myself: 'I hope it's okay ... I mean ... I'm not going to be too sick' ..." (E10).

\section{During spirometry}

The participants described the spirometry test as being strange, unsettling and painful. The emergent lexical field portrayed the spirometer as discovering a new and unimportant object. "It is a tool" (E3), "...he makes me blow in the, I don't know what..." (E4), "I blow again in the thing" (E4). As an appropriation strategy, some patients give the device a nickname. "I call it a toy ... precisely which are design to do the test...to blow in ... in the trumpet ..." (E8).

The participants described the forced expiratory manoeuvre as an uncomfortable experience. "This horrible thing really tried me" (E8). "It makes me cough like an animal" (E4). "It's too big for me" (E4). "I felt like there was no resistance ...in the device" (E2). Some even described the manoeuvre as being painful to exhale so strongly. "It hurts my head to have blown like that..." (E5). "It makes my head turn..." (E7). Nevertheless, patients were engaged and motivated to achieve the best result possible. "I tried to blow out and hold as long as possible ..." (E2). "I think I've reached the end" (E5). "I have no more oxygen in my ... in my lungs" (E6). "I'm empty..." (E3). "I breathe until I feel that I can't breathe any more" (E3). Some felt a desire or an anxiousness to perform well. "I feel like I'm not good at blowing" (E2). "As long as I stand tall... well in the rank, and the results are good, that's fine" (E5).

Participants expressed having a heightened awareness about their health status.

The participants voiced that spirometry made them conscious that there was a problem with their health. "I understand it ... since I felt it ..." (E3). "I'm not surprised ..." (E7). "It affects you" (E1). Furthermore, they expressed a realisation of their limitations. "By the finding, I had trouble expelling a lot of air" (E3). “...the inside of it ... makes a noise ..." (E9). "I say to myself ... I've lost my breath ..." (E9). "Well, it's when I heard my lungs that ... that I knew I did not blow well" (E9).

\section{After spirometry}

The participants also voiced being apprehensive about getting the results and felt conflicted between wanting to have a diagnosis and being afraid of the diagnosis. Feelings of grief were expressed when asked to recall the moment the spirometry results were announced. These expressions of grief naturally emerged according to the stages described by Kubler-Ross: ${ }^{40}$

Shock

I tell myself it was not good news ... (E3)

Well, the end of consultation... the rest was much less important for me ... (E3)

\section{Denial}

For me it's not suitable ... it's the system I do not say the device ... it's the system ..., well after I say ... he is kidding. (E8)

I thought this was a joke. (E5)

\section{Sadness and cognitive saturation}

Well, I tell you I felt shame, sadness. (E1)

I was glad when it ended, I think I had had enough for that day, I had heard enough. (E1)

\section{Anger and shame}

It's very distressing (tears)... but there is more to this side ... this mortifying side lasts longer. (E1)

If you are told that you have weakness somewhere... it's a little upsetting. (E2)

I'm afraid that ... I'll have cancer. (E10)

Well, it breaks my heart ... I have a friend who died of that .... because of cigarettes ... a heart attack. (E6)

\section{Expectation of more information}

I think ... I was expecting more explanations ... (E7)

I'm thinking ... I'm going to try to smoke less ... (E9)

I'm thinking about stopping smoking... (E6)

I think I should try to quit. (E10)

I tell myself that I smoke too much. (E9)

\section{Pain and depression}

It is like a sentence of the condemned. (E1)

\section{Rebuilding}

You know, when you have to go to war... well, it's a bit similar. (E1)

I can cope with COPD. (E1)

I tell myself she's right. (E6)

Well... I feel like I'm starting to realise. (E10)

Now, I can look to the future. (E1)

The consultation even enabled some participants to accept the disease

There's a kind ... of ... I would call it: acceptance.

(E1)

Well, it is a diagnosis that I expected. (E7)

He tells me it's a ... it's a chronic bronchitis. (E9)

The consultation that follows the spirometry test is also a meaningful part of the patient's experience. 
He concludes that I do not have asthma (...) it somehow reassures me. (E3)

I felt a little improvement with his medication ... so what happens to me is that well ... that reassures me a little bit. (E3)

\section{DISCUSSION}

\section{Summary of findings}

Before the spirometry experience, the participants were willing but expressed feeling apprehensive about discovering the reason for their ill health. During the spirometry experience, the participants described the spirometry test as being strange, unsettling and painful. After the spirometry experience, the participants also voiced renewed apprehension about the results and felt conflicted between wanting to have a diagnosis and being afraid of the diagnosis.

We observed that these elicited reports of the spirometry experience combined three characteristics of health behavioural change models: importance, opportunity and confidence. ${ }^{41}$ Importance refers to the magnitude of the problem for the patient, opportunity refers to the timing to take action and confidence is the self-belief in success. Combining these three behavioural change characteristics motivates people living with a chronic disease to engage in self-management with shared decisionmaking. 424

Our findings highlight that apart from being a diagnostic tool, spirometry is an important step for participants. In fact, the participative nature of the spirometry test, elicited as a sense of urgency, encourages the patient's drive to become actively involved in their health. This active participation was illustrated by the desire participants expressed to perform well: "I tried to blow in and hold for as long as possible" (E1). Spirometry also enabled the participants to confront the state of their own health and their limits. "I understand," "I heard my lungs," "I'm not surprised." These results show that participants understood their lungs were the source of their ill health, unlike other qualitative research studies using thematic analysis, which suggested that patients passively accepted and resigned themselves to their circumstances. ${ }^{11}$ When patients actively participate in measuring their physical limits, they gain awareness about the impact of the disease. "What are we going to find?" (E10). This shows that the patients understand the importance and magnitude of their disease as described in the motivation interviewing model. ${ }^{44}$

We also found that participants expressed this spirometry experience as an opportunity to act. They described the experience as being uncomfortable but resembled the symptoms with which they live daily. These illness perceptions are meaningful as they refer to their own life experience. After spirometry, patients expressed a cognitive intention to stop smoking. "I should try to quit" (E10).
Lastly, although the participants expressed feeling strange about the spirometry test and were forced to struggle with their symptoms, they gained confidence in their ability to manage their health with the support of their doctor, "We never know what is in store for us, but ... it's my doctor, I'm confident" (E3). Also, verbatim quotes from the debriefing indicated that participants were confident in their ability to reduce or even stop smoking, which is an important step in the process of changing behaviour. $^{41}$

\section{Strengths and limitations of the study}

To our knowledge, this is the first phenomenological study on spirometry for COPD conducted to date. Microphenomenological analysis from open elicitation interview has been used in the fields of psychiatry, pedagogy and neuroscience, however few studies have applied this technique in primary care. ${ }^{34}$

Although this micro-phenomenological-inspired analysis is limited by the qualitative nature of the study, the open elicitation interview gave us access to participant emotions during spirometry in a primary setting. Although we were aware that researcher attitudes may have influenced the data interpretation, investigator triangulation reduced this possibility of bias. Also, by employing an open elicitation interview, participants were able to retell their experience as they lived it, in their own words. This decreased the potential for sociability bias and increased the internal consistency.

The time frame explored through the interview was limited to the short period around the spirometry examination, and some participants had little insight into the spirometry experience. This may account for the unusually short interview length for a micro-phenomenological approach, which typically lasts for at least 1 hour. Other elements surrounding the spirometry experience such as the context of realisation or the relationship with the health professional involved in the spirometry test experience could have been further explored.

Although the sample size was small, it was within the recommended limits for the descriptive phenomenological approach and may have been restricted by the limited use of spirometry in primary care in France..$^{25} 45$

Thus, the experiences the participants reported appear to stimulate the right combination of these three characteristics of health behavioural change models. ${ }^{41}$ This suggests that spirometry can instigate health behavioural change and may be a key moment for patient empowerment in COPD.

Although there have been no other reports of spirometry experience using micro-phenomenology, our results are consistent with the life history of a patient with COPD and may provide a breakthrough point for change. These findings indicate that a change occurs when people with confirmed COPD have a spirometry test. These people change from a state where they are willing but apprehensive about the diagnosis, and advance to a state of acceptance. This process is similar to the stages of grief 
described by Kubler-Ross and reformulated by Boer ${ }^{46}$ in the COPD and corresponds with the stepwise processes of the change model described by Prochaska and Velicer. ${ }^{20}$

The micro-phenomenological-inspired approach adopted in this study enabled us to explore the participants' emotional experience during spirometry in primary care settings with the empathic support of their own GP. Our data on perception, cognition and emotion suggest that spirometry testing may be an optimal time for primary care clinicians to support their patients to make behavioural changes, such as increasing physical activity or reducing smoking. This reflects similar accounts where lung function testing is an opportune moment to change patient attitudes toward smoking cessation. ${ }^{47} 48$

\section{Comparison with existing literature and implications for clinical} practice

The unique choice of combining a microphenomenological analysis and an open elicitation interviewing technique highlighted that spirometry is not only a useful diagnostic tool, but also a tool to empower people with COPD to drive behavioural change. This is consistent with other studies that have explored the patient experience of a technical act where patients were more concerned with the attitude of the team and the personal attention they received. ${ }^{45}$ Moreover, a recent paper on mobile health in COPD showed that personalised feedback is needed to engage patients. ${ }^{42}$ These results highlight the various fields involved when patients experience a medical act. This suggests that there is a need to investigate the patient experience of other technical gestures in primary care to promote self-confidence in patient self-management, facilitated by a health professional's caring attitude. Physicians should allow adequate time and listen to patients' stories, and thus develop a shared understanding of the temporal aspect of the illness and patients' needs and concerns.

\section{CONCLUSIONS}

Although this study is exploratory, our findings suggest that spirometry gives patients with COPD an opportune support for behaviour change. Spirometry may allow people living with COPD to recognise their own limitations, adapt their activities to their lung capacity and to modify behaviour.

Acknowledgements The researchers thank their colleagues who provided expertise and all the patients for their participation. This article is supported by the French network of University Hospitals HUGO ('Hôpitaux Universitaires du Grand Ouest'). Editorial assistance in the preparation of this article was provided by Charlotte Wright BVM\&S(hons) MRCVS DipTrans of Speak the Speech Consultancy.

Contributors MP and MB conceived the original idea and designed the model. MB and $A B$ carried out the experiment and wrote the manuscript. $H B$ and $L P$ helped supervise the project. MP directed the project. All authors provided critical feedback and helped shape the research analysis in the manuscript.

Funding The authors have not declared a specific grant for this research from any funding agency in the public, commercial or not-for-profit sectors.

Competing interests None declared.
Patient consent for publication Not required.

Ethics approval All participants signed informed consent forms and all audio recordings were destroyed after transcription and anonymisation. Ethics committee approval was obtained by the local ethical review board (Comité central de réflexion éthique, No. 2017 047). The study was conducted in accordance with all French regulations.

Provenance and peer review Not commissioned; externally peer reviewed.

Data availability statement Data are available upon reasonable request. The full dataset is available from the corresponding author.

Open access This is an open access article distributed in accordance with the Creative Commons Attribution Non Commercial (CC BY-NC 4.0) license, which permits others to distribute, remix, adapt, build upon this work non-commercially, and license their derivative works on different terms, provided the original work is properly cited, appropriate credit is given, any changes made indicated, and the use is non-commercial. See: http://creativecommons.org/licenses/by-nc/4.0/.

\section{ORCID iD}

Maxime Pautrat http://orcid.org/0000-0001-5111-9974

\section{REFERENCES}

1 Fuhrman C, Roche N, Vergnenegre A, et al. Bronchite chronique : prévalence et qualité de vie. Rev Mal Respir 2009;26:759-68.

2 Ministère des Solidarités et de la Santé. Programme d'actions en faveur de la broncho-pneumopathie chronique obstructive (BPCO). 2005 - 2010. "Connaître, prévenir et mieux prendre en charge la BPCO". Rev Mal Respir 2005;23.

3 Ministère des Solidarités et de la Santé. Stratégie Nationale de santé 2017-2022, 2018.

4 Fraser DD, Kee CC, Minick P. Living with chronic obstructive pulmonary disease: insiders' perspectives. J Adv Nurs 2006;55:550-8.

5 Jonsdottir $\mathrm{H}$. Life patterns of people with chronic obstructive pulmonary disease: isolation and being closed in. Nurs Sci $Q$ 1998;11:160-6.

6 Bragadottir GH, Halldorsdottir BS, Ingadottir TS, et al. Patients and families realising their future with chronic obstructive pulmonary disease-A qualitative study. J Clin Nurs 2018;27:57-64.

7 Perez T, Serrier P, Pribil C, et al. [COPD and quality of life: impact of the disease in primary care in France]. Rev Mal Respir 2013;30:22-32

8 Marx G, Nasse M, Stanze H, et al. Meaning of living with severe chronic obstructive lung disease: a qualitative study. BMJ Open 2016;6:e011555.

9 Brien SB, Lewith GT, Thomas M. Patient coping strategies in COPD across disease severity and quality of life: a qualitative study. NPJ Prim Care Respir Med 2016;26:16051.

10 Pinnock H, Kendall M, Murray SA, et al. Living and dying with severe chronic obstructive pulmonary disease: multi-perspective longitudinal qualitative study. BMJ Support Palliat Care 2011;1:174-83.

11 Pinnock $\mathrm{H}$, Kendall M, Murray SA, et al. Living and dying with severe chronic obstructive pulmonary disease: multi-perspective longitudinal qualitative study. BMJ 2011;342:d142.

12 Jagana R, Bartter T, Joshi M. Delay in diagnosis of chronic obstructive pulmonary disease: reasons and solutions. Curr Opin Pulm Med 2015;21:121-6.

13 Scharloo M, Kaptein AA, Weinman JA, et al. Physical and psychological correlates of functioning in patients with chronic obstructive pulmonary disease. J Asthma 2000;37:17-29.

14 Lindgren S, Storli SL, Wiklund-Gustin L. Living in negotiation: patients' experiences of being in the diagnostic process of COPD. Int $J$ Chron Obstruct Pulmon Dis 2014;9:441-51.

15 Arne M, Emtner M, Janson S, et al. COPD patients perspectives at the time of diagnosis: a qualitative study. Prim Care Respir J 2007;16:215-21.

16 Genoe MR, Zimmer C. "At First I Couldn't Catch My Breath": Process and Strategies for Managing Chronic Obstructive Pulmonary Disease. Int J Aging Hum Dev 2018;86:191-214.

17 Bourbeau J, Bartlett SJ. Patient adherence in COPD. Thorax 2008;63:831-8.

18 Korpershoek YJ, Bruins Slot JC, Effing TW, et al. Self-management behaviors to reduce exacerbation impact in COPD patients: a Delphi study. Int J Chron Obstruct Pulmon Dis 2017;12:2735-46.

19 Cannon D, Buys N, Sriram KB, et al. The effects of chronic obstructive pulmonary disease self-management interventions on 
improvement of quality of life in COPD patients: a meta-analysis. Respir Med 2016;121:81-90.

20 Prochaska JO, Velicer WF. The transtheoretical model of health behavior change. Am J Health Promot 1997;12:38-48.

21 Labonté LE, Tan WC, Li PZ, et al. Undiagnosed chronic obstructive pulmonary disease contributes to the burden of health care use. data from the CanCOLD study. Am J Respir Crit Care Med 2016;194:285-98.

22 Gershon A, Mecredy G, Croxford R, et al. Outcomes of patients with chronic obstructive pulmonary disease diagnosed with or without pulmonary function testing. CMAJ 2017;189:E530-8.

23 Welte T, Vogelmeier C, Papi A. COPD: early diagnosis and treatment to slow disease progression. Int J Clin Pract 2015;69:336-49.

24 Ulrik CS, Løkke A, Dahl R, et al. Early detection of COPD in general practice. Int J Chron Obstruct Pulmon Dis 2011;6:123-7.

25 Buffels J, Degryse J, Heyrman J, et al. Office spirometry significantly improves early detection of COPD in general practice: the DIDASCO study. Chest 2004;125:1394-9.

26 Bouharaoua S, Combe-Cayla P, Rakotonirina S, et al. [Spirometry in primary care to screen for COPD: Feedback from a feasibility study in a semi-rural area]. Rev Mal Respir 2017;34:1037-9.

27 Bunge L, Baruch D, Plantier L, et al. [Study of the feasibility of spirometry in general practice]. Rev Mal Respir 2018:35:238-48.

28 Darmon D, Roche N, Ghasarossian C, et al. [Screening for COPD in general practice: which perspectives?]. Rev Mal Respir 2015;32:94-6.

29 Chambellan A, Housset B. [COPD screening and COPD early diagnosis]. Rev Mal Respir 2014;31:391-3.

$30 \mathrm{~J}$ oo MJ, Sharp LK, Au DH, et al. Use of spirometry in the diagnosis of COPD: a qualitative study in primary care. COPD 2013;10:444-9.

31 Hansen J. Lung age is a useful concept and calculation. Prim Care Respir J 2010;19:400-1. author reply 1.

32 VBM PC, M BI. What is it like to meditate? Methods and issues of a micro-phenomenological description of meditative experience. Conscious Stud 2017;24:170-98

33 Micoulaud-Franchi J-A BC, Vion-Dury J. L'entretien en « explicitation » en médecine : pour explorer les vécus subjectifs. Med Rev UNAFORMEC 2012;8:363-7.
34 Balzani C, Micoulaud-Franchi J-A, Yunez N, et al. L'accès aux vécus pré-réflexifs. Quelles perspectives pour la médecine en général et la psychiatrie en particulier? Annales Médico-psychologiques, revue psychiatrique 2013;171:118-27.

35 Marinker M. Why make people patients? J Med Ethics 1975;1:81-4.

36 P V. L'entretien d'explicitation. Psychologies \& Psychothérapies, 2019.

37 Vermersch P. Aide l'explicitation et retour réflexif. Psychologies \& Psychothérapies, 2004.

38 V-RA V-MC. An analysis procedure for the micro- phenomenological interview. 14. Constructivist Foundations, 2019.

39 C BM P. The validity of first-person descriptions as authenticity and coherence. Journal of Consciousness Studies 2009;16:363-404.

40 Kübler-Ross EKD. On grief and grieving: finding the meaning of grief through the five stages of loss: Simon and Schuster, 2005.

41 Miller WR, Rose GS. Toward a theory of motivational interviewing. Am Psychol 2009;64:527-37.

42 McAllister M, Dunn G, Payne K, et al. Patient empowerment: the need to consider it as a measurable patient-reported outcome for chronic conditions. BMC Health Serv Res 2012;12:157.

43 Risling T, Martinez J, Young J, et al. Evaluating patient Empowerment in association with eHealth technology: Scoping review. J Med Internet Res 2017:19:e329.

44 Resnicow K, McMaster F. Motivational interviewing: moving from why to how with autonomy support. Int J Behav Nutr Phys Act 2012;9:19.

45 Pietkiewicz PSJ. A practical guide to using interpretative phenomenological analysis in qualitative research psychology. Czas Psychol J 2014;20.

46 Boer LM, Daudey L, Peters JB, et al. Assessing the stages of the grieving process in chronic obstructive pulmonary disease (COPD): validation of the acceptance of disease and impairments questionnaire (ADIQ). Int J Behav Med 2014;21:561-70.

47 Lorenzo A, Noël F, Lorenzo M, et al. [The role of spirometry in encouraging smoking cessation in general practice. A pilot study using "lung age"]. Rev Mal Respir 2017;34:734-41.

48 Sundblad B-M, Larsson K, Nathell L. Lung function testing influences the attitude toward smoking cessation. Nicotine Tob Res 2010;12:37-42. 